\title{
Sterol Synthesis in the Human Arterial Intima
}

\author{
Aram V. Chobanian \\ From the Fifth and Sixth Medical Services, Boston City Hospital, the \\ Robert Dawson Evans Memorial Department of Clinical Research, \\ University Hospital, and the Department of Medicine, Boston \\ University School of Medicine, Boston, Massachusetts
}

\begin{abstract}
A в S T R A C T Intimal sterol synthesis was examined in isolated human arterial segments obtained at surgery or at postmortem examination. The tissues were incubated with acetate- $1-{ }^{14} \mathrm{C}$ and mevalonate- $2-{ }^{14} \mathrm{C}$ and the incorporation of these precursors into sterols was determined. Intimal sterols were isolated by multiple chromatographic techniques and purified by bromination and oxidation procedures. The results indicate that the arterial intima can incorporate acetate and mevalonate into cholesterol, cholestanol, and squalene. Cholestanol was the major sterol synthesized by the arterial wall, but cholesterol production was also consistently observed. The findings suggest that local synthesis is a potential source of sterol accumulation within the arterial wall.

The conversion of cholesterol to other sterols was also studied in terminally ill patients receiving labeled cholesterol before death. Tissue analyses revealed the presence of labeled cholestanol as well as cholesterol in the tissue 5-104 days after labeled cholesterol administration. The results demonstrate the conversion of cholesterol to cholestanol in man and suggest that the exchange of cholestanol between the blood and tissues is similar to that of cholesterol.
\end{abstract}

\section{INTRODUCTION}

The origin of cholesterol accumulation within the arterial intima has been the subject of numerous investigations. Previous studies have indicated that

This study was presented in part at the annual meeting of the American Physiology Society, 19 April 1967, and appeared in abstract form (1).

Received for publication 15 May 1967 and in revised form 26 October 1967. plasma cholesterol is an important source of arterial cholesterol $(2-4)$, but the role of local intimal synthesis of cholesterol in its accumulation has not been clearly defined. Siperstein, Chaikoff, and Chernick demonstrated cholesterol synthesis in isolated rabbit and chicken aorta (5) and similar results were noted in calf and swine arteries by Werthessen, Milch, Redmond, Smith, and Smith (6) and in rat aorta by Dady, Deming, Raeff, and Brun (7). However, the studies of Azarnoff with human arteries have suggested that human intimal cholesterol synthesis does not occur (8).

The present investigation was designed to reexamine the question of arterial sterol synthesis in isolated segments of human arteries. In addition, the body conversion of cholesterol to other sterols and the deposition of these sterols in the intima has been studied in terminally ill patients receiving labeled cholesterol. Multiple chromatographic techniques were utilized in a complementary manner for the isolation and identification of intimal sterols. The results indicate that the human arterial intima has the capacity to incorporate labeled acetate and mevalonate into both cholestanol (dihydrocholesterol) and cholesterol with the major incorporation present into the cholestanol fraction. The studies also indicate that conversion of cholesterol to cholestanol in the body can occur, and that exchange of cholestanol between the blood and tissues takes place.

\section{METHODS}

Human arteries which were removed at surgery ( $\mathrm{Pa}$ tients $1-3,5$, and 7 ) or at postmortem examination within $4 \mathrm{hr}$ of death (Patients 4, 6, and 8) were prepared for incubation as previously described (9). The tissues were suspended in $10 \mathrm{ml}$ of incubation solution (9) containing 
either acetate- $1{ }^{14} \mathrm{C}(1.0 \mu \mathrm{c} / \mathrm{ml}, \mathrm{SA}, 53.0 \mathrm{mc} / \mathrm{mmole}),{ }^{1}$ or mevalonate- $2-{ }^{14} \mathrm{C}(0.5 \mu \mathrm{c} / \mathrm{ml}, \mathrm{SA}, 1.22 \mathrm{mc} / \mathrm{mmole}) .^{1}$ Incubations were carried out for $6 \mathrm{hr}$ at $37^{\circ} \mathrm{C}$ in a Dubnoff shaker in an atmosphere of $95 \% \quad \mathrm{O}_{2}-5 \% \quad \mathrm{CO}_{2}$. The total amount of incubated tissue ranged from 0.5 to $3.0 \mathrm{~g}$ with 0.3 to $0.5 \mathrm{~g}$ in each incubation flask. The studies were carried out under sterile conditions and cultures of the incubation solution at the termination of study revealed no growth of microorganisms. Atherosclerosis was graded by visual inspection (4).

After incubation, the tissues were washed five times, blotted, minced, and homogenized in chloroform-methanol $2: 1(\mathrm{v} / \mathrm{v})$. Aliquots of the minced tissue were dried to a constant weight and the result expressed in terms of dry tissue weight. The tissue lipids were extracted by the method of Folch, Lees, and Sloane Stanley (10). Aliquots of the lipid extract were saponified with $\mathrm{KOH}$ and the sterols precipitated with digitonin (4). The sterol content and radioactivity of the digitonin precipitate were measured as previously described (4).

Thin-layer chromatography (TLC) system 1. The chloroform-methanol tissue extract was transferred to pointed tubes and reduced to a smaller volume under a stream of nitrogen. The intimal lipids were separated into lipid groups by TLC on silica gel $\mathrm{G}^{2}$ (11). The plates were exposed to iodine vapors and the individual spots circled and identified by comparison with standards of lecithin, ${ }^{3}$ cholesterol, ${ }^{4}$ oleic acid, ${ }^{5}$ tripalmitin, ${ }^{6}$ cholesteryl oleate, ${ }^{4}$ and squalene. ${ }^{3}$ The sterol and sterol esters were scraped from the plates and extracted at $60^{\circ} \mathrm{C}$ in centrifuge tubes with $3 \times 10 \mathrm{ml}$ of benzene. The cholesterol ester fraction (also containing squalene) was saponified with $\mathrm{KOH}$ and an aliquot was re-run on TLC using the same system. The free sterols were combined and the total sterol content and radioactivity determined.

TLC system 2. The major portion of the extract from TLC system 1 was again reduced to a small volume and the 27-carbon (C-27) sterols were isolated by TLC on silica gel $\mathrm{G}$ prestained with Rhodamine $6 \mathrm{G}^{7}$ according to the method of Avigan, Goodman, and Steinberg (12). The sterols were eluted as described above and the sterol content and radioactivity measured. The addition of unlabeled lanosterol 4 or ergosterol 4 to the extract as carriers before chromatography did not affect the distribution of sterol radioactivity on the chromatoplates. The recovery of both cholesterol and cholestanol standards from the silica gel after chromatography and elution averaged $98 \%$ (range $97-101 \%$ ). Cholestanol was quantitated in the recovery experiments by the anthrone color reaction (13).

TLC system 3. Aliquots of the eluate from TLC system 2 were analyzed by TLC to separate cholesterol,

\footnotetext{
1 New England Nuclear Corp., Boston, Mass.

2 Brinkmann Instruments Inc., Westbury, N. Y.

3 Sigma Chemical Co., St. Louis, Mo.

4 Steroids Inc., New York.

5 Applied Science Laboratories Inc., State College, Pa.

6 Mann Research Laboratories Inc., New York.

${ }^{7}$ Matheson Co., Inc., Norwood, Ohio.
}

cholestanol, and 7-dehydrocholesterol ( $\Delta 5,7$ cholestadienol) using silica gel $\mathrm{G}$ presprayed with $25 \% \mathrm{Ag}$ $\mathrm{NO}_{3}$ (14). The samples were run with and without carrier cholestanol and 7-dehydrocholesterol. The plates were sprayed with distilled $\mathrm{H}_{2} \mathrm{O}$ and the sterols identified by comparison with known standards. The sterols were extracted with $50 \%$ ethanolic ammonia and benzene (14) and the radioactivity assayed. The recovery of cholesterol and cholestanol after chromatography and elution averaged 78 and $74 \%$, respectively.

TLC system 4. To isolate lathosterol ( $\Delta^{7}$-cholestenol from cholestanol and cholesterol, portions of the extracts from TLC system 3 were analyzed on silica gel $G$ using $40 \mathrm{~cm}$ glass plates and benzene-ethyl acetate $20: 1$ as described by Avigan et al. (12). Carrier lathosterol 6 was added before chromatography. The sterols were extracted with benzene and their radioactivities assayed.

TLC system 5. TLC of squalene was performed on silica gel $\mathrm{G}$ on aliquots of the eluate from TLC system 1 that contained squalene, according to the method of Goodman (15). Carrier squalene was added before chromatography. The squalene band was isolated and the radioactivity determined as described (9).

Column chromatography. Aliquots of the extract from TLC system 2 were analyzed by silicic acid-super-cel chromatography as described by Frantz (16). Fractions of $5 \mathrm{ml}$ each were collected from the column and color was developed in representative aliquots by the Liebermann-Burchard reaction after 1.5 and $30 \mathrm{~min}$. All the sterol present was of the slow reacting type. A peak with an $R_{f}$ value equal to cholesterol represented from 98.8 to $99.7 \%$ of the total sterols applied to the column with the remainder appearing in the chromatographic fraction with $R_{f}$ value similar to desmosterol. Cholesterol was not resolved from cholestanol or 7-dehydrocholesterol by this technique. The fractions were recombined into groups corresponding to the chromatographic behavior of the different sterols and the sterol radioactivity was determined. The recovery of both cholesterol and cholestanol averaged $97 \%$.

Gas-liquid chromatography (GLC). Portions of the eluate from TLC system 2 were analyzed by GLC on methyl silicone gum (General Electric) (SE-30) and methyl fluoroalkyl silicone (QF-1) packed columns 8 with a Model 400 Series chromatograph 8 equipped with an effluent splitter. With SE-30, the retention times of cholesterol and cholestanol were virtually identical but on QF-1, the retention time of cholestanol was 1.1 times that of cholesterol. After injection the compounds represented by each peak on the chromatographic tracing and also the intervening areas were collected individually on Teflon tubes at the GLC outflow portal. The material was extracted from the tubes with $5 \times 5 \mathrm{ml}$ of warm benzene and then assayed for ${ }^{14} \mathrm{C}$-radioactivity. Approximately $50-100 \mu \mathrm{g}$ of sterol was applied to the column with each injection. The recovery of sterol after chromatography and elution averaged $27 \%$.

Purification of cholesterol by dibromide formation.

\footnotetext{
${ }^{8}$ F \& M Scientific Co., Avondale, Pa.
} 
Aliquots of the eluate from TLC system 2 were purified by dibromide formation according to the method of Schwenk and Werthessen (17) and the cholesterol specific activity assayed. The recovery of cholesterol averaged $65 \%$.

Purification of cholestanol by oxidation. The cholestanol-containing fraction from TLC system 3 in Patient 8 was also treated with formic acid and hydrogen peroxide after addition of $50 \mathrm{mg}$ cholestanol as carrier (18). The product was partitioned between petroleum ether and methanol and the cholestanol was oxidized with perbenzoic acid and chromatographed as described (19). The cholestanol so obtained was crystallized from acetonemethanol to constant specific activity.

Tissue studies in patients receiving labeled cholesterol. Postmortem tissue samples were obtained in three patients who died after receiving either $20 \mu \mathrm{c}$ of cholesterol-4- ${ }^{14} \mathrm{C}$ (Patient 10) or 500 and $1000 \mu \mathrm{c}$ cholesterol-7- ${ }^{3} \mathrm{H}(\mathrm{Pa}-$ tients 9 and 11, respectively). The tissue lipids were extracted with chloroform-methanol $2: 1$ and the sterols were separated by TLC systems $1,2,3$, and 4 . The sterol content and radioactivity were measured as described above. With the liver and aorta of Patient 11, the cholestanol fraction from TLC system 3 was oxidized and recrystallized as described above and the cholestanol specific activity determined.

Purification of both ${ }^{3} \mathrm{H}$ and ${ }^{14} \mathrm{C}$-labeled cholesterol standards by TLC systems $1,2,3$, and 4 revealed that
$99.7 \%$ of the radioactivity was recovered with cholesterol and the remaining $0.3 \%$ with cholestanol.

In all of the analytical procedures, the results were corrected to $100 \%$ recovery. In representative arterial segments heat-killed in boiling $\mathrm{H}_{2} \mathrm{O}$ for $1 \mathrm{~min}$ before incubation with either ${ }^{14} \mathrm{C}$-acetate or ${ }^{14} \mathrm{C}$-mevalonate, no radioactivity was recovered in any of the arterial sterol fractions.

\section{RESULTS}

A flow chart outlining the sequence of methods and the results obtained in a representative case (Patient 5) is illustrated in Fig. 1.

Incorporation of ${ }^{14} \mathrm{C}$-acetate and ${ }^{14} \mathrm{C}$-mevalonate into total sterols. The incorporation of labeled acetate into the digitonin precipitable material (Table I) ranged from 34.7 to $3380 \mathrm{dpm} / \mathrm{mg}$ of cholesterol ( 5250 to $24,300 \mathrm{dpm} / \mathrm{g}$ of intima) and that of mevalonate (Table II) from 170 to 2650 $\mathrm{dpm} / \mathrm{mg}$ of cholesterol (9640 to $33,400 \mathrm{dpm} / \mathrm{g}$ of intima). The total incorporation of acetate and mevalonate into intimal sterols which were isolated by the separation of the lipid groups (TLC system 1) was $44-81 \%$ of that precipitated with digitonin. The sterol radioactivity was confined

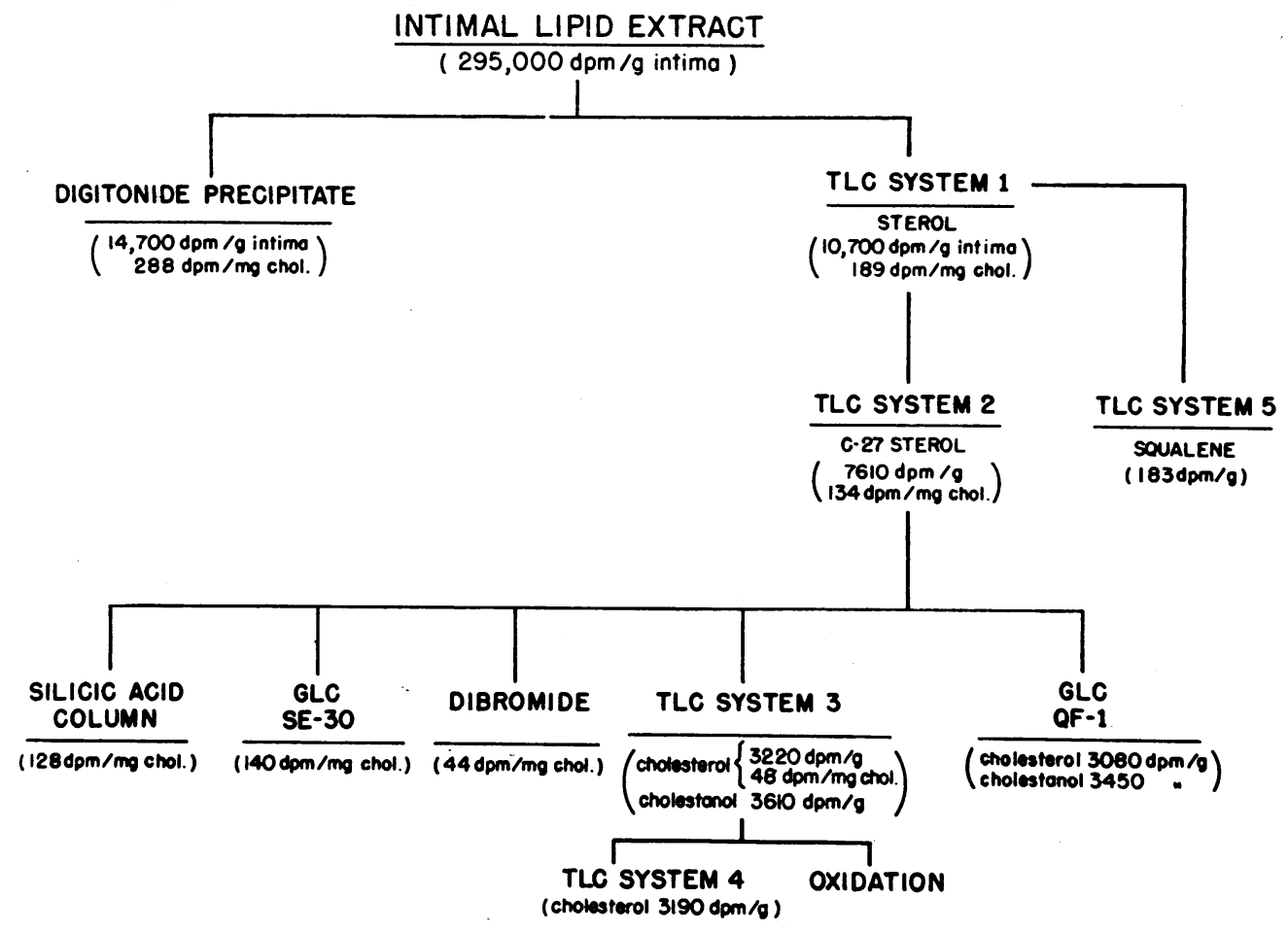

FIGURE 1 Flowsheet for the analysis of intimal sterols and the results observed in a representative case (Patient 5). 
TABLE I

Incorporation of Acetate-1 ${ }^{14} \mathrm{C}$ into Sterol in the Human Arterial Intima

\begin{tabular}{|c|c|c|c|c|c|c|c|}
\hline \multirow[b]{2}{*}{ Patient } & \multirow[b]{2}{*}{$\begin{array}{l}\text { Age and } \\
\text { sex }\end{array}$} & \multirow[b]{2}{*}{ Tissue } & \multirow{2}{*}{$\begin{array}{c}\text { Degree } \\
\text { athero- } \\
\text { sclerosis } \\
\left(0-4^{+}\right)\end{array}$} & \multirow[b]{2}{*}{$\begin{array}{l}\text { Cholesterol } \\
\text { content }\end{array}$} & \multicolumn{3}{|c|}{ Sterol radioactivity } \\
\hline & & & & & $\begin{array}{c}\text { Digitonin } \\
\text { precipitate }\end{array}$ & $\begin{array}{c}\text { TLC } \\
\text { system } 1\end{array}$ & $\begin{array}{c}\text { TLC } \\
\text { system } 2\end{array}$ \\
\hline 1 & $13 \mathrm{M}$ & $\begin{array}{r}\text { Femoral } \\
\text { artery }\end{array}$ & 0 & $\begin{array}{c}m g / g d r y w t \\
7.20\end{array}$ & $3380^{d p m /}$ & ng of chole. & erol \\
\hline 2 & $63 \mathrm{~F}$ & $\begin{array}{l}\text { Abdominal } \\
\text { aneurysm }\end{array}$ & $4^{+}$ & 55.2 & 95.1 & 54.0 & 40.5 \\
\hline 3 & $72 \mathrm{M}$ & $\begin{array}{l}\text { Abdominal } \\
\text { aneurysm }\end{array}$ & $4^{+}$ & 40.2 & 212 & 130 & 68.7 \\
\hline 4 & $74 \mathrm{~F}$ & $\begin{array}{l}\text { Abdominal } \\
\text { aorta }\end{array}$ & $4^{+}$ & 180 & 34.7 & 16.7 & 11.2 \\
\hline 5 & $70 \mathrm{~F}$ & $\begin{array}{l}\text { Thoracic } \\
\text { aneurysm }\end{array}$ & $4^{+}$ & 51.1 & 288 & 189 & 134 \\
\hline 6 & $76 \mathrm{~F}$ & $\begin{array}{c}\text { Thoracic } \\
\text { aorta }\end{array}$ & $3-4^{+}$ & 55.5 & - & 20.7 & 16.0 \\
\hline
\end{tabular}

essentially to the unesterified or free sterols with only a small portion in the sterol esters. The major radioactivity measured in the sterol ester fraction was distributed between the fatty acid portion of the sterol ester molecule, the squalene moiety (see below), and an unidentified fraction which after saponification and rechromatography had an $R_{f}$ value of 1.0. In the tissues incubated with acetate, $2.0-5.1 \%$ of the total lipid radioactivity was isolated with the free sterols, whereas with mevalonate, $5.2-11.8 \%$ of the lipid radioactivity was recovered there.

The incorporation of substrate into C-27 sterols
(TLC system 2) ranged from 11.2 to $134 \mathrm{dpm} / \mathrm{mg}$ of cholesterol for acetate and from 62.0 to 132 $\mathrm{dpm} / \mathrm{mg}$ of cholesterol for mevalonate. $53-77 \%$ of the radioactivity isolated with the free sterols (TLC system 1) was present in the C-27 sterol group. The remaining radioactivity was recovered from the TLC plate at the origin and at the edge of the solvent front. No radioactivity was recovered in association with lanosterol or ergosterol when these materials were added as carriers before chromatography. Further analysis of the C-27 sterol containing fraction by silicic acidsuper-cel column chromatography revealed all the

TABLE II

Incorporation of Mevalonate-2-14C into Sterol in the Human Arterial Intima

\begin{tabular}{|c|c|c|c|c|c|c|c|}
\hline \multirow[b]{2}{*}{ Patient } & \multirow[b]{2}{*}{$\begin{array}{l}\text { Age and } \\
\text { sex }\end{array}$} & \multirow[b]{2}{*}{ Tissue } & \multirow{2}{*}{$\begin{array}{c}\text { Degree } \\
\text { athero- } \\
\text { sclerosis } \\
\left(0-4^{+}\right)\end{array}$} & \multirow[b]{2}{*}{$\begin{array}{l}\text { Cholesterol } \\
\text { content }\end{array}$} & \multicolumn{3}{|c|}{ Sterol radioactivity } \\
\hline & & & & & $\begin{array}{c}\text { Digitonin } \\
\text { precipitate }\end{array}$ & $\begin{array}{c}\text { TLC } \\
\text { system } 1\end{array}$ & $\begin{array}{c}\text { TLC } \\
\text { system } 2\end{array}$ \\
\hline & & & & $m g / g d r y w t$ & \multicolumn{3}{|c|}{$d p m / m g$ of cholesterol } \\
\hline 2 & $63 \mathrm{~F}$ & $\begin{array}{l}\text { Abdominal } \\
\text { aneurysm }\end{array}$ & $4^{+}$ & 56.7 & 170 & 138 & 104 \\
\hline 3 & $72 \mathrm{M}$ & $\begin{array}{l}\text { Abdominal } \\
\text { aneurysm }\end{array}$ & $4^{+}$ & 41.0 & 332 & 208 & 132 \\
\hline 7 & $15 \mathrm{M}$ & $\begin{array}{c}\text { Axillary and } \\
\text { brachial } \\
\text { arteries }\end{array}$ & 0 & 12.6 & 2650 & 1420 & - \\
\hline 8 & $68 \mathrm{~F}$ & $\begin{array}{l}\text { Abdominal } \\
\text { aorta }\end{array}$ & $3^{+}$ & 62.8 & 189 & 83.5 & 62.0 \\
\hline
\end{tabular}




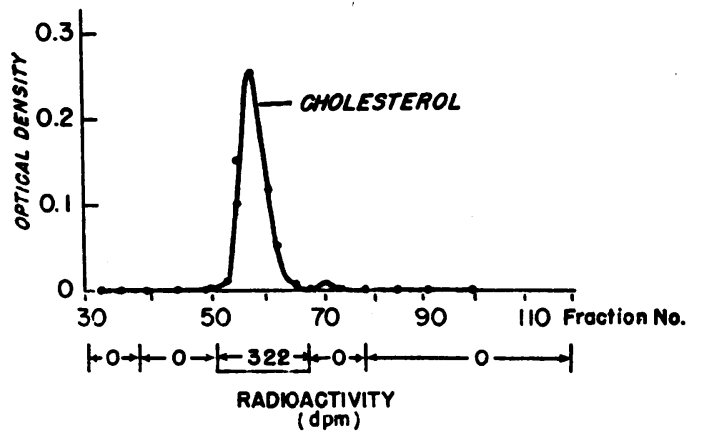

FIGURE 2 Silicic acid-super-cel chromatography of intimal C27-sterols in Patient 5.

radioactivity to be confined to the major sterolcontaining peak which had an $R_{f}$ value equal to cholesterol and cholestanol (Fig. 2). No labeled material was present in the chromatographic fractions with $R_{f}$ values equivalent to lanosterol, des-

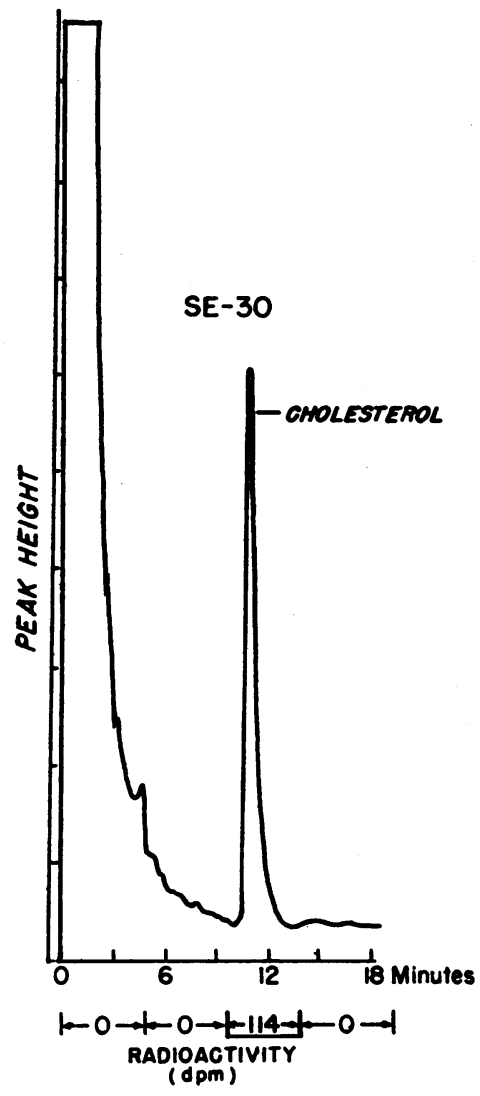

Figure 3 GLC analysis of intimal C27-sterols on methyl silicone gum (General Electric) $(\mathrm{SE}-30)$ in Patient 5. Column conditions: $4 \mathrm{ft} \times 4 \mathrm{~mm}$ glass column; $3.0 \%$ SE-30 methyl silicone on $80-100$ mesh Diatoport-S; $255^{\circ} \mathrm{C} ; 20$ psi.

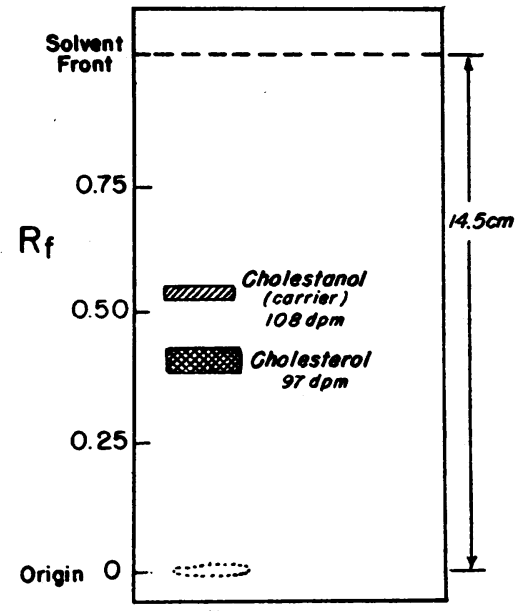

FIGURE 4 TLC analysis (system 3) for intimal cholesterol and cholestanol in Patient 5.

mosterol, or lathosterol. Likewise with GLC analysis on SE-30 (Fig. 3), the total radioactivity was confined to the peak with retention time equal to cholesterol or cholestanol. The specific activities of the C-27 sterols, as measured by TLC system 2 , column chromatography, and GLC on SE-30, were comparable.

Incorporation of ${ }^{14} \mathrm{C}$-acetate and ${ }^{14} \mathrm{C}$-mevalonate into cholestanol and cholesterol. $51-71 \%$ of the radioactivity in the $\mathrm{C}-27$ sterols was isolated by TLC system 3 (Fig. 4) in the fraction chromatographically identical to cholestanol, whereas the remaining $29-49 \%$ was present in the cholesterol containing moiety (Table III). No 7-dehydrocholesterol radioactivity was apparent. Essentially similar results were observed with GLC using the QF-1 column (Fig. 5). The intimal content of cholesterol represented less than $1 \%$ of total intimal sterols. The specific activity of cholestanol

TABLE III

Incorporation of Acetate-1 $1{ }^{14} \mathrm{C}$ and Mevalonate-2-14 $\mathrm{C}$ into Squalene, Cholesterol, and Cholestanol in the Human Arterial Intima

\begin{tabular}{|c|c|c|c|c|}
\hline \multirow[b]{2}{*}{ Patient } & \multirow[b]{2}{*}{ Substrate } & \multicolumn{3}{|c|}{${ }^{14} \mathrm{C}$-radioactivity } \\
\hline & & Squalene & Cholesterol & Cholestanol \\
\hline & & \multicolumn{3}{|c|}{$d p m / g$ of dry intima } \\
\hline 2 & Mevalonate & - & 1360 & 3290 \\
\hline 5 & Acetate & 183 & 3220 & 3610 \\
\hline 6 & Acetate & 124 & 431 & 505 \\
\hline 8 & Mevalunate & 284 & 1808 & 1870 \\
\hline
\end{tabular}


was greater than 100 times that of cholesterol, but could not be measured accurately in view of the small quantity of cholestanol present. The cholesterol and cholestanol containing fractions when further analyzed by TLC system 4 did not contain labeled lathosterol.

The specific activity of cholestanol isolated by TLC system 3 decreased by $3 \%$ after oxidation and recrystallization procedures.

Using phosphate rather than lactate buffer in the incubation solution, or varying the incubation time from 3 to $12 \mathrm{hr}$ did not influence the distribution of sterol radioactivity. In Patient 2, after $3 \mathrm{hr}$ of incubation $65 \%$ of the sterol radioactivity was present as cholestanol and the remainder as cholesterol. In Patient 6, cholestanol represented $54 \%$ of the total sterol radioactivity at $4 \mathrm{hr}$ and $57 \%$ at $12 \mathrm{hr}$ with the remainder at both time periods as cholesterol.

Incorporation of acetate and mevalonate into squalene. The incorporation of acetate into the fraction chromatographically identical to squalene was 124 and $183 \mathrm{dpm} / \mathrm{g}$ of intima and that of mevalonate $284 \mathrm{dpm} / \mathrm{g}$ of intima (Table III).

Dibromide purification of cholesterol. The cholesterol specific activity in extracts from TLC system 2 after bromination was $19-36 \%$ of the sterol specific activity before bromination.

Tissue cholestanol and cholesterol radioactivity after labeled cholesterol administration. The aortic cholestanol radioactivity ranged from $0.4 \%$ of total sterol radioactivity at 5 days to $4 \%$ at 104

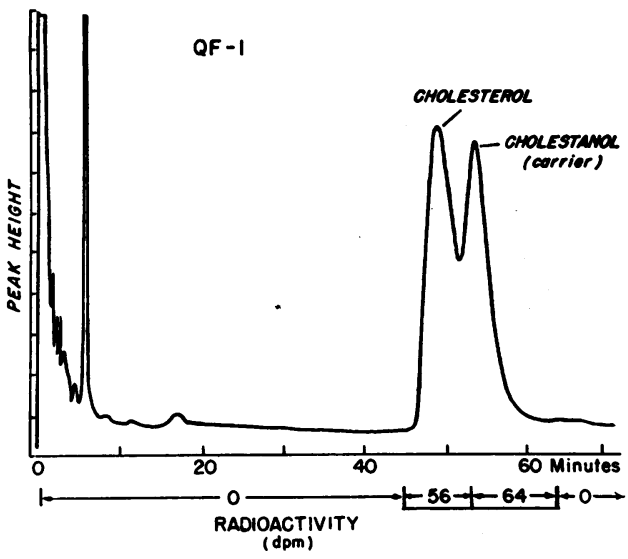

FIGURE 5 GLC analysis of intimal sterols on methyl fluoroalkyl silicone (QF-1). Column conditions: $4 \mathrm{ft} \times$ $4 \mathrm{~mm}$ glass column; $3.8 \% \mathrm{QF}-1$ fluoroalkyl silicone on 80-100 mesh Diatoport S; $200^{\circ} \mathrm{C} ; 20$ psi.
TABLE IV

Tissue Cholesterol and Cholestanol Radioactivity after Administration of Labeled Cholesterol

\begin{tabular}{|c|c|c|c|c|c|}
\hline \multirow[b]{3}{*}{ Patient } & \multirow[b]{3}{*}{ Time* } & \multirow[b]{3}{*}{ Tissue } & \multicolumn{3}{|c|}{ Sterol radioactivity } \\
\hline & & & \multirow[b]{2}{*}{ Cholesterol } & \multirow[b]{2}{*}{$\begin{array}{l}\text { Choles- } \\
\text { tanol }\end{array}$} & \multirow{2}{*}{$\begin{array}{c}\text { Cholestanol } \\
\text { Cholestanol } \\
+ \\
\text { choles- } \\
\text { terol }\end{array}$} \\
\hline & & & & & \\
\hline & days & & \multicolumn{2}{|c|}{$d p m / g$ of $d r y w t$} & \\
\hline 9 & 5 & Aorta & 7,460 & 30 & 0.004 \\
\hline \multirow[t]{3}{*}{10} & 20 & Liver & 6,540 & 361 & 0.05 \\
\hline & & Kidney & 16,600 & 851 & 0.05 \\
\hline & & Aorta & 16,500 & 345 & 0.02 \\
\hline \multirow[t]{3}{*}{11} & 104 & Blood & 16,400 & 568 & 0.03 \\
\hline & & Liver & 10,700 & 442 & 0.04 \\
\hline & & Aorta & 19,300 & 875 & 0.04 \\
\hline
\end{tabular}

* Time, interval between labeled cholesterol administration and death of patient.

days. At 20 days, the cholestanol radioactivity in the liver and kidney were $5 \%$ of that of total sterols, and at 104 days, the values for blood and liver were 3 and $4 \%$, respectively, of the total sterol radioactivity (Table IV). The specific activity of cholestanol in the aorta of Patient 11 decreased by $2 \%$ with oxidation and recrystallization, whereas that of the liver diminished by $6 \%$.

\section{DISCUSSION}

These studies indicate that the isolated human arterial intima has the capacity to incorporate acetate and mevalonate into cholestanol and cholesterol with the major incorporation into the cholestanol fraction. The latter finding was unexpected since cholestanol has not previously been reported to be the major sterol synthesized from these substrates. Although the present results might be due to experimental artifact created by the in vitro system, the general similarity of results in all arteries with both acetate and mevalonate as labeled substrate and with variations in the duration of incubation and in the composition of the incubation mixture argues against this.

The significance, if any, of arterial cholestanol synthesis in the pathogenesis of the atherosclerotic lesion remains to be determined. Experimental studies in birds have revealed that chronic cholestanol feeding can produce severe atherosclerosis which appears similar to that induced by choles- 
terol (20). In man, cholestanol is present in small amounts in the arterial wall as well as in blood and other tissues and represents approximately $1 \%$ of the total sterol content of atherosclerotic plaques (21).

The results also suggest that the human arterial intima, like that of the chicken, rabbit, calf, and rat (5-7), can synthesize cholesterol, but the quantitative role of this endogenous synthesis in the intimal accumulation of cholesterol is unclear. Previous investigations in rabbits and chickens have shown that most of the cholesterol deposited in the arterial wall is derived from the plasma $(3,22)$. In man, the importance of plasma as the major source of arterial cholesterol has likewise been suggested by the similarity in composition of the fatty acids in the cholesterol esters of plasma and intima $(23,24)$ and by the comparable cholesterol specific activities in plasma and normal arterial intima after the administration of labeled cholesterol (4). In atheromatous plaques where the cholesterol appears to exist in a compartment that is not freely exchangeable with plasma cholesterol (25), local synthesis could conceivably represent an important source of arterial cholesterol. However, the absence of appreciable cholestanol accumulation in atherosclerotic lesions, even though it appeared to be the major sterol synthesized by the intima, would argue against this.

Small amounts of labeled cholestanol were present in all tissues of patients receiving labeled cholesterol which suggests that conversion of cholesterol to cholestanol had occurred. Although the administered cholesterol contained minute quantities of a labeled contaminant which was chromatographically identical to cholestanol, it is unlikely that this contaminant was the sole source of labeled tissue cholestanol since the ratio of labeled cholestanol to cholesterol in each tissue analyzed was greater than that present in the administered material. These results are consistent with those of Rosenfeld, Zumoff, and Hellman who recently demonstrated the transformation of cholesterol to cholestanol in man (26). A similar capacity for converting cholesterol to cholestanol is also found in guinea pigs (27) but presumably not in rats (28).

Labeled cholestanol represented only $0.4 \%$ of the cholesterol radioactivity in the intima 5 days after labeled cholesterol administration. At 20 days, however, the intimal cholestanol radioactivity had risen to $2 \%$ of that of cholesterol and the ratio of labeled cholestanol/cholesterol in the intima was approximately $40 \%$ of that in the liver and kidney. Finally, by 104 days, the labeled cholestanol/cholesterol ratios in the blood, liver, and intima were essentially comparable. These findings suggest that the exchange of cholestanol between blood and tissues may be similar to that of cholesterol and, perhaps, of desmosterol, as well $(4,29)$. The results also indicate that intimal cholestanol can originate from the plasma as well as from local synthesis.

A small amount of labeled material, chromatographically identical with squalene on 2 TLC systems, was isolated from the incubated arterial segments. Whereas the identity of the material was not conclusively proven, it resembled squalene and presumably represented an intermediate in the sterol biosynthesis pathway of the intima. Recent studies by Robertson have also demonstrated arterial squalene synthesis using intimal cell cultures (30). During incubation periods ranging from 3 to $12 \mathrm{hr}$, measurable radioactivity in sterols other than cholestanol and cholesterol was not observed and delineation of the pathway of intimal sterol synthesis has not been possible. Nevertheless, the vastly greater intimal specific activity of cholestanol than cholesterol suggests that the major pathway of intimal cholestanol synthesis from acetate and mevalonate does not involve cholesterol as an intermediate. In the rat and guinea pig liver, studied in vitro, however, cholesterol has been reported to be an important precursor of cholestanol (31).

The results disagree in part with the findings of Azarnoff who could not demonstrate significant cholesterol synthesis within the human intima even though he had observed incorporation of the labeled precursors into digitonin precipitable material (8). An explanation for the variation in results is not readily apparent. Perhaps differences in the preparation of tissue for incubation (intimal slices in his investigation as compared wth intact segments reported here) may have been significant. Another possible but unlikely explanation might be that since the cholesterol radioactivity was quite low and represented only a small percentage of that in the digitonin precipitate, it may 
have gone undetected previously, because of the loss of radioactivity with dibromide purification and the dilution of radioactivity introduced by carrier cholesterol. At any event, the persistence of cholesterol radioactivity that followed the numerous purification procedures used in the present experiments strongly supports the presence of intimal cholesterol synthesis.

\section{ACKNOWLEDGMENTS}

The author expresses his thanks to Suzanne Fortin Doyle and Evelyn Kocur for their technical assistance, and to Peter Brecher and Dr. Herbert Wotiz for the GLC analyses. The author is also indebted to Dr. William Hollander for his helpful criticisms and to Dr. Robert W. Wilkins for review of the manuscript.

This study was supported in part by grants HE-07299 and HE-1536 from the U. S. Public Health Service, and the U. A. Whitaker Fund.

\section{REFERENCES}

1. Chobanian, A. V. 1967. Sterol metabolism in the human arterial intima. Federation Proc. 26: 262. (Abstr.)

2. Biggs, M. W., D. Kritchevsky, D. Colman, J. W. Gofman, H. B. Jones, F. T. Lindgren, G. Hyde, and T. P. Lyon. 1952. Observations on the fate of ingested cholesterol in man. Circulation. 6: 359.

3. Newman, H. A. I., and D. B. Zilversmit. 1962. Quantitative aspects of cholesterol flux in rabbit atheromatous lesions. J. Biol. Chem. 237: 2078.

4. Chobanian, A. V., and W. Hollander. 1962. Body cholesterol metabolism in man. I. The equilibration of serum and tissue cholesterol. J. Clin. Invest. 41: 1732.

5. Siperstein, M. D., I. L. Chaikoff, and S. S. Chernick. 1951. Significance of endogenous cholesterol in arteriosclerosis: Synthesis in arterial tissue. Science 113: 747.

6. Werthessen, N. T., L. J. Milch, R. F. Redmond, L. L. Smith, and E. C. Smith. 1954. Biosynthesis and concentration of cholesterol by the intact surviving bovine aorta in vitro. Am. J. Physiol. 178: 23.

7. Daly, M. M., Q. B. Deming, V. M. Raeff, and L. M. Brun. 1963. Cholesterol concentration and cholesterol synthesis in aortas of rats with renal hypertension. J. Clin. Invest. 42: 1606.

8. Azarnoff, D. L. 1958. Species differences in cholesterol biosynthesis by arterial tissue. Proc. Soc. Exptl. Biol. Med. 98: 680.

9. Chobanian, A. V., and W. Hollander. 1966. Phospholipid synthesis in the human arterial intima. J. Clin. Invest. 45: 932.

10. Folch, J., M. Lees, and G. H. Sloane Stanley. 1957. A simple method for the isolation and purification of total lipides from animal tissues. J. Biol. Chem. 226: 497.
11. Mangold, H. K. 1961. Thin-layer chromatography of lipids. J. Am. Oil Chemists' Soc. 38: 708.

12. Avigan, J., DeW. S. Goodman, and D. Steinberg. 1963. Thin-layer chromatography of sterols and steroids. J. Lipid Res. 4: 100.

13. Vahouny, G. V., R. M. Mayer, J. H. Roe, and C. R. Treadwell. 1960. Determination of 3- $\beta$-hydroxy sterols with anthrone reagent. Arch. Biochem. Biophys. 86: 210.

14. Truswell, A. S., and W. D. Mitchell. 1965. Separation of cholesterol from its companions, cholestanol and $\Delta^{7}$-cholestenol, by thin-layer chromatography. J. Lipid Res. 6: 438.

15. Goodman, DeW. S. 1964. Squalene in human and rat blood plasma. J. Clin. Invest. 43: 1480.

16. Frantz, I. D., Jr. 1963. Chromatography of unesterified sterols on silicic acid-super-cel. J. Lipid Res. 4: 176 .

17. Schwenk, E., and N. T. Werthessen. 1952. Studies on the biosynthesis of cholesterol. III. Purification of $\mathrm{C}^{14}$-cholesterol from perfusions of livers and other organs. Arch. Biochem. Biophys. 40: 334.

18. Fieser, L. F., and S. Rajagopalan. 1949. Selective oxidation with $n$-bromosuccinimide. II. Cholestane-3 3 ,

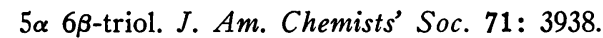

19. Rosenfeld, R. S., and L. Hellman. 1958. The biochemical transformation of cholestenone to cholesterol. J. Biol. Chem. 233: 1089.

20. Nichols, C. W., Jr., S. Lindsay, and I. L. Chaikoff. 1955. Production of atherosclerosis in birds by the prolonged feeding of dihydrocholesterol. Proc. Soc. Exptl. Biol. Med. 89: 609.

21. Mosbach, E. H., J. Blum, E. Arroyo, and S. Milch. 1963. A new method for the determination of dihydrocholesterol in tissues. Anal. Biochem. 5: 158.

22. Dayton, S. 1959. Turnover of cholesterol in the artery walls of normal chickens. Circulation Res. 7: 468.

23. Böttcher, C. J. F., F. P. Woodford, C. Ch. Ter Haar Romeny-Wachter, E. Boelsma-Van Houte, and C. M. Van Gent. 1960. Fatty-acid distribution in lipids of the aortic wall. Lancet. 1: 1378.

24. Tuna, N., and H. K. Mangold. 1963. Fatty acids of the atheromatous plaque. In International Symposium on the Evolution of the Atherosclerotic Plaque. R. J. Jones, editor. University of Chicago Press, Chicago. $85-108$.

25. Hollander, W., D. M. Kramsch, and G. Inoue. 1967. The metabolism of cholesterol, lipoproteins, and acid mucopolysaccharides in normal and atherosclerotic vessels. Prog. Biochem. Pharmacol. 4: 270.

26. Rosenfeld, R. S., B. Zumoff, and L. Hellman. 1967. Conversion of cholesterol injected into man to cholestanol via a 3-ketonic intermediate. J. Lipid Res. 8: 16.

27. Werbin, H., I. L. Chaikoff, and M. R. Imada. 1962. $5 \alpha$-Cholestan- $3 \beta$-ol: Its distribution in tissues and its synthesis from cholesterol in the guinea pig. J. Biol. Chem. 237: 2072. 
28. Harold, F. M., D. D. Chapman, and I. L. Chaikoff. 1957. Metabolism of cholestanol. I. Fate of cholestanol-4-C is in the rat. II. Metabolic interrelations of cholestanol, epicholesterol, and $\Delta^{4}$-cholestenone. $J$. Biol. Chem. 224: 609.

29. Chobanian, A. V., and W. Hollander. 1965. Tissue distribution of cholesterol and 24-dehydrocholesterol during chronic triparanol therapy. J. Lipid. Res. 6: 37.
30. Robertson, A. L. 1967. Transport of plasma lipoproteins and ultrastructure of human arterial intimacytes in culture. In Lipid Metabolism in Tissue Culture Cells. G. H. Rothblat and D. Kritchevsky, editors. Wistar Institute Press, Philadelphia. 115.

31. Shefer, S., S. Milch, and E. H. Mosbach. 1965. Biosynthesis of $5 \alpha$-cholestan-3 $\beta$-ol in rat and guinea pig liver in vitro. J. Lipid Res. 6: 33. 